NBER WORKING PAPER SERIES

\title{
FINANCIALLY CONSTRAINED FLUCTUATIONS IN AN EVOLVING NETWORK ECONOMY
}

Domenico Delli Gatti

Mauro Gallegati

Bruce C. Greenwald

Alberto Russo

Joseph E. Stiglitz

Working Paper 14112

http://www.nber.org/papers/w14112

\author{
NATIONAL BUREAU OF ECONOMIC RESEARCH \\ 1050 Massachusetts Avenue \\ Cambridge, MA 02138 \\ June 2008
}

We are grateful for insightful comments and criticisms to participants to the Eastern Economic Association meeting, New York City, February 2007, the Net-Work-shop at Catholic University in Milan, April 2007 and the Annual Meeting of the Italian Economists' Society in Turin, October 2007. Special thanks to Duncan Foley, whose detailed comments have been especially useful. The views expressed herein are those of the author(s) and do not necessarily reflect the views of the National Bureau of Economic Research.

NBER working papers are circulated for discussion and comment purposes. They have not been peerreviewed or been subject to the review by the NBER Board of Directors that accompanies official NBER publications.

(C) 2008 by Domenico Delli Gatti, Mauro Gallegati, Bruce C. Greenwald, Alberto Russo, and Joseph E. Stiglitz. All rights reserved. Short sections of text, not to exceed two paragraphs, may be quoted without explicit permission provided that full credit, including $\odot$ notice, is given to the source. 
Financially Constrained Fluctuations in an Evolving Network Economy

Domenico Delli Gatti, Mauro Gallegati, Bruce C. Greenwald, Alberto Russo, and Joseph E.

Stiglitz

NBER Working Paper No. 14112

June 2008

JEL No. E3

\begin{abstract}
We explore the properties of a credit network characterized by inside credit - i.e. credit relationships connecting downstream (D) and upstream (U) firms - and outside credit - i.e. credit relationships connecting firms and banks. The structure of the network changes over time due to the preferred-partner choice rule: each agent chooses the partner who charges the lowest price. The net worth of $\mathrm{D}$ firms turns out to be the driver of fluctuations. U production, in fact, is determined by demand of intermediate inputs on the part of $\mathrm{D}$ firms and production of the latter is financially constrained, i.e. determined by the availability of internal finance proxied by net worth. The output of simulations shows that at the macroeconomic level a business cycle can develop as a consequence of the complex interaction of the agents' financial conditions. We can also reproduce the main stylized facts of firms' demography, i.e. the power law distribution of firms' size and the Laplace distribution of firms' growth rates.
\end{abstract}

Domenico Delli Gatti

Istituto di Teoria Economica

Universita' Cattolica

Largo Gemelli, 1

20123 Milano

domenico.delligatti@unicatt.it

Mauro Gallegati

Dipartimento di Economia

Facolta' di Economia Giorgio Fua'

Universita' Politecnica delle Marche

Piazzale Martelli, 8

60121 Ancona

mauro.gallegati@univpm.it
Alberto Russo

Dipartimento di Economia

Facolta' di Economia Giorgio Fua'

Universita' Politecnica delle Marche

Piazzale Martelli, 8

60121 Ancona

albrusso@univpm.it

Joseph E. Stiglitz

Uris Hall, Columbia University

3022 Broadway, Room 814

New York, NY 10027

and NBER

jes322@columbia.edu

Bruce C. Greenwald

Columbia University

611 Uris Hall

New York, NY 10027

bg7@columbia.edu 


\section{Introduction}

Networks are the main subject of a rapidly growing literature which applies the conceptual and analytical tools already developed in sociology, computer science and physics to economics and/or provides new notions and methods to be applied specifically to economic phenomena. Recent books by Jackson (2008), Vega-Redondo (2007) and Goyal (2007) describe the frontier of research on economic networks. ${ }^{1}$

The complex pattern of credit relationships is a natural research issue to be dealt with by means of network analysis. It is straightforward to think of agents as nodes and of debt contracts as links in a credit network. There are indeed influential examples of network analysis applied to credit networks.

Allen and Gale (2000), for instance, put forward a theory of "financial contagion" in a network model of the interbank market. In this case, however, the networks considered are very simple and easy to study because they consist of few nodes organized in canonical forms. A non-negligible and growing literature has developed from these premises on the network of the interbank market (Freixas, Parigi and Rochet, 2000; Furfine, 2003; Boss, Elsinger, Summer and Thurner, 2004; Iori et al., 2006; Nier et al., 2007).

A different but no less important line of network research (Boissay, 2006; Battiston et al., 2007) focuses on the trade-credit relationships within the corporate sector, i.e. among suppliers of intermediate goods and producers of final goods along the "supply chain".

These strands of network literature analyze specific credit relationships: among banks on the interbank market or among firms along the supply chain. Building upon ideas expounded first in Stiglitz and Greenwald (2003, chapter 7), in Delli Gatti et al. (2006) we have pursued a more general and "encompassing" line of research. We have modelled a credit network consisting of households, firms and banks. Agents are linked by inside credit (i.e. credit relationships connecting firms belonging to different layers of the same industry - the corporate sector - or connecting banks on the interbank market) and outside credit (i.e. credit relationships connecting agents belonging to different sectors, i.e. banks and firms).

In that paper, the network is static, i.e. its structure does not change

\footnotetext{
${ }^{1}$ See also the extensive surveys on network formation by Jackson and on learning in networks by Goyal in the the book edited by Demange and Wooders (2005). Caldarelli (2007) analyzes networks from the physicist's point of view. His book presents plenty of applications to different fields, economics being only one of them.
} 
over time. The specific contribution of the present paper is the introduction of a mechanism for the endogenous evolution of the network structure, the preferred-partner choice rule.

Jackson (2005) distinguishes between a random graph approach to network formation, borrowed from physics, and the game theoretic approach specifically designed to deal with economic networks. The former is, in a sense, "mechanical": network formation is purely stochastic or the product of an ad hoc algorithm. The latter focuses on "equilibrium" networks, where links are formed as a consequence of cost-benefit analysis on the part of self-interested agents.

The approach followed in the present paper is half-way between the two: the preferred partner choice rule allocates links to nodes as a consequence of the search for the lowest price. In every period, an agent in search of a partner in a transaction - a customer in search of a supplier, a firm in search of a bank - chooses the partner who posts the minimum price in a randomly selected subset of agents; if the minimum price is lower than the price the agent paid to the old partner in the previous period, he will switch to the new partner, otherwise he will stick to the old one. The number of links connecting the nodes changes over time so that the topology of the network is also in a process of continuous evolution.

Central to this picture is information, not only about the conditions of the parties in a credit relationship but also about the incentives that they face. Lenders have to assess the risk involved in extending credit to borrowers, i.e. their ability and willingness to fulfill debt obligations. But information is asymmetric so that such an assessment is at best incomplete: all the issues crucial to modelling borrowers' and lenders' behaviour in an asymmetric information context are relevant also in designing the network of credit relationships. In this context, a simple and easily available indirect sign of the borrowers' creditworthiness is a measure of their financial soundness captured, for instance, by net worth.

In the credit network we consider, households are final consumers laboursuppliers. The corporate sector consists of two layers of firms. Downstream (D) firms produce consumption goods, while upstream (U) firms supply intermediate inputs to D firms. Banks extend credit to firms in both layers. D firms are pure borrowers: they borrow from $U$ firms (trade credit) and from banks (bank loans). Banks are pure lenders: they lend to D and U firms. U firms are borrowers and lenders at the same time: they borrow from banks and lend to D firms. 
Adopting a financing hierarchy perspective, we assume that the scale of production of D firms is constrained only by their net worth. Since U output is determined by the input requirements of $\mathrm{D}$ firms, the net worth of $\mathrm{D}$ firms turns out to be the main driver of fluctuations. Changes in the net worth of $\mathrm{D}$ firms, in fact, brings about changes in the same direction of $\mathrm{U}$ production. An unexpected shock to a $\mathrm{D}$ firm affects the credit relationship between the firm and its supplier, on the one hand, and between the firm and the bank on the other.

If the shock is large enough, the D firm may be unable to fulfill debt commitments and may go bankrupt. The bankruptcy of a borrower would be irrelevant if, so to speak, the agent were an "island". In a networked economy, however, bankruptcy will not be an isolated and therefore insignificant phenomenon.

Interdependence may assume different forms. For instance, the bankruptcy of a D firm may bring about the default of the $\mathrm{U}$ firm with which it interacts along the supply chain. Moreover "bad debt" - i.e. non-performing loans affect the net worth of banks, which can also go bankrupt. If they manage to survive, they will react to the deterioration of borrowers' financial conditions increasing the interest rate. The interest rate hike leads to more bankruptcies and eventually to a bankruptcy chain: "the high rate of bankruptcy is a cause of the high interest rate as much as a consequence of it" (Stiglitz, Greenwald, 2003: 145).

Therefore, the default of one agent can bring about an avalanche of bankruptcies which may be due to direct interaction between the bankrupt firm and its supplier or to indirect interaction through the banking system. In the latter case, in fact, while the proximate cause of the bankruptcy of a certain firm in the middle of the avalanche is the interest rate hike, the remote cause is the bankruptcy of a firm at the beginning of the avalanche that forced the banks to push interest rates up. ${ }^{2}$

The endogenous evolution of credit interlinkages through the preferred partner choice rule affects the extent of bankruptcies' diffusion: the bankruptcy of an highly connected agent increases the probability of bankruptcy diffusion across the network.

\footnotetext{
${ }^{2}$ Delli Gatti et al. (2005) emphasize the role of indirect interaction in the development of an avalanche of bankruptcies. In the agent-based economy considered in that paper, in fact there is no customer-supplier network so that bankruptcies due to direct interaction cannot be observed by construction.
} 
All in all, we consider four markets: consumption goods, intermediate inputs, labour and credit. "Quantities", i.e. the amount of consumption and intermediate goods produced, labour employed and credit extended are not directly affected by "prices". They depend, instead, as we have already pointed out above, on the financial conditions of the agents involved.

Prices, however, play an essential role in (i) shaping the evolving topology of the network and (ii) determining the degree of agents' financial vulnerability.

As to (i), in two of the markets considered, i.e. the markets for intermediate inputs and for bank loans, the preferred partner choice rule implies that the price charged by a supplier to a customer - which incorporates the interest rate on commercial paper - and the interest rate on bank loans affect the number of clients of each $U$ firm and the number of loan applications to each bank respectively and therefore impacts upon the evolution of network connectivity.

As to (ii), prices are important determinants of profits, which in turn affect the accumulation of net worth and financial fragility. The financial vulnerability of an agent therefore is affected by the dynamics of prices.

On the markets for consumption goods and on the labour market, "prices" are exogenously determined and play a less relevant role. Following GreenwaldStiglitz (1993), we assume that on the market for consumption goods, prices are governed by a random process (we elaborate a little bit on this issue below). As to the labour market, we appeal to real rigidity of one sort or another so that we feel entitled to take the real wage as given and constant. In these cases, for the sake of simplicity and clarity we have admittedly adopted a very crude "theory" of prices. We will relax these assumption and enrich the theory in further extensions of the present model. Our conjecture, however, is that qualitatively the main results of the model - in particular the output of simulations - will not be remarkably affected by this relaxation.

We study the properties of the network by means of simulations, which show that a business cycle at the macroeconomic level can develop as a consequence of the complex interaction of the agents' financial conditions. In other words, statistical regularities emerge as a self-organised process at the aggregate level. At the same time, the main facts of firms' demography (such as power law distribution of firms' size and Laplace distribution of growth rates) emerge endogenously. In the case of the preferred choice rule the firms' size distribution and the degree distribution are much more asymmetric than in the case of random matching. 
The paper is organized as follows. In section 2 we sketch the main assumption concerning the economy under scrutiny. Sections 3 and 4 are devoted to the price/quantity decisions of agents, i.e. firms and banks respectively. In section 5 we explain the mechanism governing the choice of the partner. In section 6 we analyze the main determinants of profits. Section 7 is devoted to the relationship between profits, net worth and bad debt. In section 8 we discuss the results of the simulations. Section 9 concludes.

\section{The environment}

We model a multi-sector economy in discrete time $(t=1,2, \ldots, T)$ populated by a multitude of heterogeneous agents. The economy consists of three sectors: a downstream sector consisting of $I$ firms (labeled by the index $i=1,2, \ldots, I)$, an upstream sector with $J$ firms $(j=1,2, \ldots, J)$ and a banking sector consisting of $Z$ banks $(z=1,2, \ldots, Z)$. In order to keep the analysis simple, the number of firms and of banks is exogenous. ${ }^{3}$

There are two goods, a consumption good and an intermediate good. D firms produce a perishable consumption good using labor and intermediate goods. For simplicity and as a first approximation to a more realistic setting, we assume that firms sell all the output they produce at a stochastic price.

U firms produce the intermediate good "on demand" with a technology that requires only labor. Therefore $U$ firms do not hold inventories of intermediate goods. We are ruling out by construction the possibility of avalanches of output due to the mismatch of demand and supply of intermediate goods along a supply chain à la Bak, Chen, Scheinkman and Woodford (1993).

The financial side of the economy is characterized by two lending relationships: (i) downstream and upstream firms obtain credit from banks; (ii) downstream firms buy intermediate goods from upstream firms by means of a commercial credit contract.

The structure of the network of expenditure, production and credit relationships evolves endogenously due to the decentralized interaction among agents, on the basis of a simple incentive mechanism which we have labelled the preferred-partner choice: in every period each D firm looks for the U

\footnotetext{
${ }^{3}$ Since in our framework agents can leave the market due to bankruptcy, in order to preserve constancy of the number of agents we have to apply a one-to-one replacement procedure when an agent goes bankrupt.
} 
firm with the lowest price of intermediate goods; at the same time each firm searches for the bank with the lowest interest rate.

\section{Firms}

The core assumption of the model is that the scale of activity of the $i-t h$ D firm at time $\mathrm{t}$ - i.e. the level of production $Y_{i t}$ - is an increasing concave function of its financial robustness, captured by net worth $A_{i t}$ :

$$
Y_{i t}=\phi A_{i t}^{\beta}
$$

where $\phi>1,0<\beta<1$ are parameters, uniform across D firms. The equation above represents the financially constrained output function.

There are (at least) two rationales for (1). First, it can be thought of as a simple rule of thumb in a world in which (i) bounded rationality prevents the elaboration of optimizing decision-making processes and (ii) asymmetric information between borrowers and lenders yields a financing hierarchy in which net worth ranks first.

Alternatively one can think of equation (1) as the solution of an optimization problem on the part of the firm. According to Greenwald and Stiglitz (1993) for instance the problem of the firm consists in maximizing expected profits $E\left(\pi_{i}\right)$ net of bankruptcy $\operatorname{costs} C_{i}$ weighted by the probability of bankruptcy $\Omega_{i}$. From the definition of profits follows that they are an increasing function of output $Y_{i}$ given net worth $A_{i}: \pi_{i}=\pi\left(Y_{i} ; A_{i}\right)$. Bankruptcy costs are assumed to be increasing with the firm's size: $C_{i}=C\left(Y_{i}\right)$. Finally, from the definition of the probability of bankruptcy, it turns out that it is increasing with the scale of activity, given net worth: $\Omega_{i}=\Omega\left(Y_{i} ; A_{i}\right)$. An increase of financial fragility, in fact, captured by a reduction of net worth, brings about an increase of the probability of bankruptcy. In the end the Greenwald-Stiglitz characterization of the problem of the firm is:

$$
\max _{Y_{i}} V\left(Y_{i} ; A_{i}\right)=E\left(\pi\left(Y_{i} ; A_{i}\right)\right)-C\left(Y_{i}\right) \Omega\left(Y_{i} ; A_{i}\right)
$$

whose solution is

$$
Y_{i}=\arg \max V\left(Y_{i} ; A_{i}\right)=f\left(A_{i}\right)
$$

with $f^{\prime}>0$. Equation (1) can be considered an element in the set of functional forms consistent with (2). 
By construction, the second interpretation of (1) is grounded on more stringent requirements of rationality than those implicit in (i) above. However, it is still true that asymmetric information yields a financing hierarchy as assumed in (ii).

The concavity of the financially constrained output function (1) captures the idea that there are "decreasing returns" to financial robustness: the increase in output associated to a given increase of net worth is lower if the firm is already financially robust. If the financially constrained output function is the same for all D firms, by Jensen's inequality an increase in the variance of financial conditions brings about a reduction of average (and therefore aggregate) output of D firms.

For simplicity we assume that the production function of each $\mathrm{D}$ firm is of the Leontief type: $Y_{i}=\min \left(\frac{1}{\delta_{d}} N_{i}, \frac{1}{\gamma} Q_{i}\right)$ where $N_{i}$ is employment and $Q_{i}$ are intermediate inputs, $\delta_{d}>0$ and $\gamma>0$. Therefore, each $\mathrm{D}$ firm has the following labor and intermediate goods requirement functions: $N_{i t}=$ $\delta_{d} Y_{i t}, Q_{i t}=\gamma Y_{i t}$. Taking into account (1), in the end, both the demand for labor and the demand for intermediate goods of D firms are increasing and concave functions of their financial conditions: $N_{i t}=\delta_{d} \phi A_{i t}^{\beta}, Q_{i t}=\gamma \phi A_{i t}^{\beta}$.

Final goods are sold at a stochastic price $u_{i t}$. For the sake of simplicity, we assume that $u_{i t}$ is a random variable uniformly distributed on the support $(0,2)$. We can provide the following rationale for this apparently restrictive assumption. Let the demand of the $i-t h$ commodity in period $\mathrm{t}$ be $d\left(u_{i t}, \delta_{i t+1}\right)$ where $u_{i t}$ is the relative price of the $i-t h$ commodity and $\delta_{i t}$ is a stochastic demand disturbance specific to the market in question. Let supply be $s_{i t}$. By assumption $s_{i t}$ is made up of the quantities produced by a "large number" of producers so that the contribution of each firm to total supply is negligible. In equilibrium $u_{i t}=f\left(\delta_{i t}, s_{i t}\right)$ i.e. the relative price is an increasing function of the demand disturbance, given the predetermined supply. If demand is sufficiently elastic, changes in supply do not affect the relative price significantly so that the relative price is essentially an increasing function of random demand. A high realization of $u_{i t}$ can be thought of as a regime of high demand which drives up the relative price of the commodity in question. In a regime of low demand, the realization of $u_{i t}$ turns out to be low and may push the firm out of the market if it is "too low", i.e. if it makes the net worth of the firm negative.

Upstream firms produce the intermediate good by means of a linear technology which employs only labor: $Q_{j t}=\frac{1}{\delta_{u}} N_{j t}$ where $\delta_{u}>0$. For simplicity, we assume an asymmetric structure of the D-U network: many D firms can 
be linked to a single $\mathrm{U}$ firm but each $\mathrm{D}$ firm has only one supplier of intermediate goods.

In each period the supplier - say the $j-t h$ firm - receives orders from a set of D customers which will be denoted by $\Phi_{j}$. Since each D firm looks for the $\mathrm{U}$ firm with the lowest price of intermediate goods, by construction the number of elements of $\Phi_{j}$ depends on the price $p_{j t}$ that the upstream firm charges to its customers: the lower the price, the higher the number of $\mathrm{D}$ customers of the $j-t h$ supplier of intermediate goods.

The price the supplier is charging is defined as $p_{j t}=1+r_{j t}$ where $r_{j t}$ is the interest rate on trade credit. We assume that the level of $r_{j t}$ depends on the financial condition of the $\mathrm{U}$ firm:

$$
r_{j t}=\alpha A_{j t}^{-\alpha}
$$

with $\alpha>0$. In words, the interest rate on commercial paper charged to each and every $\mathrm{D}$ firm belonging to $\Phi_{j}$ is decreasing with the financial soundness of the $U$ firm. If the $U$ firm is in good shape from the financial point of view, it will be eager to extend trade credit at more favourable terms to its D customers.

In principle, the interest rate on trade credit charged by the $j-t h \mathrm{U}$ firm should be affected also by the financial conditions of the borrowers, i.e. of the $\mathrm{D}$ firms in the set $\Phi_{j}$. In order to keep the framework as simple as possible, however, we have assumed that asymmetric information prevents a correct assessment of the financial conditions of the borrowers. Therefore the interest rate on trade credit incorporates only the financial condition of the lender.

While the scale of production of D firms is financially constrained - i.e. it is determined by their degree of financial robustness - the scale of production of $U$ firms is demand constrained, i.e. it is determined by the demand of intermediate goods on the part of $\mathrm{D}$ firms. Therefore, the financial conditions of $\mathrm{D}$ firms are the driving force also for the production of $\mathrm{U}$ firms. The more robust, on average, D firms, the higher their scale of activity and the demand for labour and intermediate goods so that the higher will be, on average, the scale of activity of $U$ firms. For instance, the demand of intermediate goods - and therefore the scale of production - of the $j$ - th $\mathrm{U}$ firm will be $Q_{j t}=$ $\gamma \sum_{i \in \Phi_{j}} Y_{i t}=\gamma \phi \sum_{i \in \Phi_{j}} A_{i t}^{\beta}$ and the demand for labor will be $N_{j t}=\delta_{u} \gamma \phi \sum_{i \in \Phi_{j}} A_{i t}^{\beta}$. 


\section{Banks}

Firms face a financing hierarchy in which internal finance ranks first and bank loans second. Therefore, by assumption, the financing gap, i.e. the difference between the firm's expenditures and internal finance, is filled by means of credit. For $U$ firms, the financing gap is the difference between the wage bill and net worth. As to D firms, expenditures consist of wages and the cost of intermediate goods. In order to keep the analysis as simple as possible, however, we assume that also for $\mathrm{D}$ firms the financing gap is the difference between the wage bill and net worth. This means that the acquisition of intermediate goods can be financed by means of trade credit, not by bank loans.

Accordingly, the demand of credit is equal to $B_{x t}=W_{x t}-A_{x t}$ where $W_{x t}=w N_{x t}$ is the firm's wage bill ( $x=i$ for $\mathrm{D}$ firms, $j$ for $\mathrm{U}$ firms). We assume that the real wage $w$ is constant and uniform across firms. By assumption, moreover, labour is abundant so that firms do not face any labour shortage at the pre-determined real wage.

Self-financed firms, i.e. firms with a level of net worth sufficient to finance the wage bill, do not demand credit. From the expression above follows that the demand for credit of the $i-t h \mathrm{D}$ firm is

$$
B_{i t}=w N_{i t}-A_{i t}=w \delta_{d} \phi A_{i t}^{\beta}-A_{i t}
$$

so that a $\mathrm{D}$ firm is self financed if it has net worth $A_{i t} \geq \hat{A} \equiv\left(w \delta_{d} \phi\right)^{\frac{1}{1-\beta}}$.

As to $\mathrm{U}$ firms, the demand for credit of the $j-t h \mathrm{U}$ firm is

$$
B_{j t}=w N_{j t}-A_{j t}=w \delta_{u} \gamma \phi \sum_{i \in \Phi_{j}} A_{i t}^{\beta}-A_{j t}
$$

so that a $\mathrm{U}$ firm is self financed if it has net worth $A_{j t} \geq \hat{A}_{j} \equiv w \delta_{u} \gamma \phi \sum_{i \in \Phi_{j}} A_{i t}^{\beta}$. The higher the net worth of D customers of the $\mathrm{U}$ firm, the less likely it is that the U firm will be self financed.

For simplicity, we assume an asymmetric structure of the firms-banks network: many firms can be linked to a single bank but each firm has only one supplier of loans. The set of customers of the $z-t h$ bank will be denoted by $\Phi_{z}$. We assume that each bank has a certain degree of market power. Since each firm looks for the bank with the lowest interest rate, by construction the number of elements of $\Phi_{z}$ depends on the interest rate the bank charges 
to its customers: the lower the interest rate, the higher the number of firms applying for loans to the $z-t h$ bank.

The $z-t h$ bank adopts the following rule in setting the interest rate on loans to the $x-t h$ borrower $(x=i$ for $\mathrm{D}$ firms, $j$ for $\mathrm{U}$ firms):

$$
r_{z t}^{x}=\sigma A_{z t}^{-\beta}+\theta\left(l_{x t}\right)^{\theta}
$$

where $A_{z t}$ is the net worth of the $z-t h$ bank and $l_{x t}=B_{x t} / A_{x t}$ is the leverage ratio of the $x-t h$ firm, $\sigma$ and $\theta$ positive parameters. Accordingly, the interest rate on bank loans is (i) decreasing with the financial soundness of the bank (proxied by the bank's net worth $A_{z t}$ ) and (ii) increasing with the firms' leverage ratio.

The rationale of (i) is obvious: if the bank is in good shape from the financial point of view, it will be eager to extend credit at more favourable terms. As to (ii), we simply assume that the firm penalizes financially fragile firms. In a sense, we adopt the principle according to which the interest rate charged by the lender incorporates an external finance premium increasing with leverage and therefore inversely related to the borrower's net worth. ${ }^{4}$

Notice that the leverage ratio of the $i-t h \mathrm{D}$ firm is

$$
l_{i t}=B_{i t} / A_{i t}=w \delta_{d} \frac{Y_{i t}}{A_{i t}}-1=w \delta_{d} \phi A_{i t}^{-(1-\beta)}-1
$$

i.e it is decreasing with net worth. Therefore, in the end, the interest rate charged by the $z-t h$ bank to the $i-t h \mathrm{D}$ firm will be:

$$
r_{z t}^{i}=\sigma A_{z t}^{-\beta}+\theta\left(w \delta_{d} \phi A_{i t}^{-(1-\beta)}-1\right)^{\theta}
$$

i.e. it will be a decreasing function of the net worth of the bank and of the firm.

The situation is different in the case of $\mathrm{U}$ firms. The leverage of the $j-t h$ $\mathrm{U}$ firm is

$$
l_{j t}=B_{j t} / A_{j t}=w \delta_{u} \frac{Q_{j t}}{A_{j t}}-1=\frac{w \delta_{u} \gamma \phi}{A_{j t}} \sum_{i \in \Phi_{j}} A_{i t}^{\beta}-1
$$

\footnotetext{
${ }^{4}$ In a sense in our model the bank behaves as a lender in a Bernanke-Gertler (1989, 1990) world characterized by asimmetryc information and costly state verification. See Bernanke, Gertler and Gilchrist (1999) for a comprehensive exposition of the approach.
} 
since $Q_{j t}=\gamma \phi \sum_{i \in \Phi_{j}} A_{i t}^{\beta}$ as shown above. The leverage of $U_{j}$ firm therefore is decreasing with its own net worth but increasing with the net worth of the downstream customers.

The interest rate charged by the $z-t h$ bank to the $j-t h \mathrm{U}$ firm will be:

$$
r_{z t}^{j}=\sigma A_{z t}^{-\beta}+\theta\left(\frac{w \delta_{u} \gamma \phi}{A_{j t}} \sum_{i \in \Phi_{j}} A_{i t}^{\beta}-1\right)^{\theta}
$$

i.e. it will be a decreasing function of the net worth of the bank and of the $j-t h$ firm but an increasing function of the net worth of the D customers. This may be counterintuitive but it is obvious in our context: the higher the net worth of D customers, the higher their demand for intermediate goods, the higher the debt - and therefore the leverage ratio, other things being equal - that $U$ suppliers have to accept in order to finance the wage bill and production and the higher the interest rate charged by the bank to the U-firm.

\section{Partners}

Each agent has to choose not only the quantity and the price of the good to be exchanged but also the partner to exchange with: a D firm has to choose a U partner and a bank; a U firm has to choose a bank.

Each $\mathrm{D}$ firm has a (productive and credit) relationship with a $\mathrm{U}$ firm. Initially, i.e. at time $t=1$, the network of firms is random, i.e. the links among $\mathrm{D}$ and $\mathrm{U}$ firms are established at random. Therefore, for instance the D firm indexed by $i\left(D_{i}\right)$ ends up linked to the $\mathrm{U}$ firm indexed by $j_{0}\left(U_{j_{0}}\right)$. In each of the subsequent periods, the network changes endogenously according to a preferred-partner choice rule (with noise) which is defined as follows:

- with (a small) probability $\varepsilon$ the D firm chooses a partner (i.e. a U supplier) at random;

- with probability $1-\varepsilon$ the D firm chooses a partner looking at the prices of a randomly selected number - say $M$ - of U firms;

- if the miminum observed price - say the price of $U_{j_{1}}$ - is lower than the price of $U_{j_{0}}$, then $D_{i}$ will switch to $U_{j_{1}}$; 
- otherwise, $D_{i}$ will stick to $U_{j_{0}}$.

Therefore, the number of links connecting $\mathrm{D}$ nodes to a certain $\mathrm{U}$ node changes over time due to the changing price charged by the $\mathrm{U}$ firm so that the topology of the network is also in a process of continuous evolution. The total number of nodes, however, is constant.

The preferred-partner choice rule applies also to the relationship between (both $\mathrm{D}$ and $\mathrm{U}$ ) firms and banks. At time $t=1$ the links among firms and banks are established at random. For instance, firm $D_{i}$ ends up linked to bank $z_{0}\left(B_{z_{0}}\right)$. Afterwards, with probability $1-\varepsilon$ each firm looks at the interest rate charged by a randomly selected number - say $N$ - of banks. If the miminum observed interest rate - say the one charged by $B_{z_{1}}$ - is lower than the one charged by $B_{z_{0}}$, then $D_{i}$ will switch to $B_{z_{1}}$; otherwise, it will stick to $B_{z_{0}}$.

The procedure to choose the partner is activated in every period - i.e. with the same frequency of price/quantity decisions - but the partner is changed less frequently, i.e. only when one of the prices the agent observes is lower than the one charged by the existing partner. By construction, therefore, the relationships between firms of different industries and between firms and banks last longer than the transaction period.

\section{Profits}

The profit of the $i-t h \mathrm{D}$ firm is $\pi_{i t}=u_{i t} Y_{i t}-\left(1+r_{z t}^{i}\right) B_{i t}-\left(1+r_{j t}\right) Q_{i t}$ where $u_{i t}$ is the stochastic price, $Y_{i t}$ is output, $r_{z t}^{i}$ is the interest rate charged by $B_{z}$ to $D_{i}, r_{j t}$ is the interest rate charged by $U_{j}$ and $Q_{i t}$ is the amount of intermediate input that $D_{i}$ has bought from $U_{j}$.

Recalling that $Q_{i t}=\gamma Y_{i t}$, output is financially constrained as shown in (1) and $B_{i t}$ is defined as in (4) we can rewrite the equation above as:

$$
\pi_{i t}=\left[u_{i t}-\left(1+r_{j t}\right) \gamma-\left(1+r_{z t}^{i}\right) w \delta_{d}\right] \phi A_{i t}^{\beta}+\left(1+r_{z t}^{i}\right) A_{i t}
$$

Since $r_{z t}^{i}$ and $r_{j t}$ are defined as in (8) and (3) respectively, in the end $D_{i}$ 's profit is a function of its own net worth and of the net worth of the $\mathrm{U}$ firm and of the bank.

Other things being equal, an increase of $A_{i t}$ affects $D_{i}$ 's profit for three reasons: 
- it makes output increase (scale effect);

- it makes leverage decrease so that the interest rate charged by the bank decreases too ( $D$ leverage effect);

- it makes the financing gap decrease. This effect is captured by the last term in the LHS of (11) (financing gap effect).

The scale effect can be either positive (if the expression in brackets is positive, i.e. if the relative price is "sufficiently high" or the interest rates are "sufficiently low") or negative (if the opposite holds true). The D leverage and the financing gap effects are unambiguously positive.

$D_{i}$ 's profit is also affected by the financial conditions of the $\mathrm{U}$ supplier and of the bank through the following externalities:

- an increase of $A_{j t}$ makes $D_{i}$ 's profit increase because it makes the interest rate charged by the supplier go down ( $U$ net worth effect);

- an increase of $A_{z t}$ makes $D_{i}$ 's profit increase because it makes the interest rate charged by the bank go down ( $B$ net worth effect).

The profit of the $j-t h$ upstream firm is $\pi_{j t}=\left(1+r_{j t}\right) Q_{j t}-\left(1+r_{z t}^{j}\right) B_{j t}$. Notice that $Q_{j t}=\gamma \phi \sum_{i \in \Phi_{j}} A_{i t}^{\beta}$, and $B_{j t}$ is defined as in (5) so that in the end we get:

$$
\pi_{j t}=\left[\left(1+r_{j t}\right)-\left(1+r_{z t}^{j}\right) w \delta_{u}\right] \gamma \phi \sum_{i \in \Phi_{j}} A_{i t}^{\beta}+\left(1+r_{z t}^{j}\right) A_{j t}
$$

Since $r_{z t}^{j}$ is defined as in (10), $U_{j}$ 's profit is a function of the net worth of the agents involved, i.e. the $\mathrm{U}$ firm itself, the set $\Phi_{j}$ of its $\mathrm{D}$ customers and the bank.

An increase of $A_{j t}$ affects $U_{j}$ 's profit for three reasons:

- it makes $U_{j}$ 's leverage decrease, so that the interest rate charged by the bank decreases too (U leverage effect);

- it makes the financing gap decrease. This effect is captured by the last term in the LHS of (12) (financing gap effect);

- it makes the price charged to D customers decrease (U net worth effect). 
The $U$ leverage and the financing gap effects are positive while the $U$ net worth effect is negative.

$U_{j}$ 's profit is also affected by the financial conditions of $\mathrm{D}$ customers and of the bank through the following externalities:

- an increase of $A_{z t}$ makes $U_{j}$ 's profit increase because it makes the interest rate charged by the bank go down ( $B$ net worth effect);

- an increase of the net worth of the D customers $\sum_{i \in \Phi_{j}} A_{i t}^{\beta}$ affects U output (scale effect).

The bank's B net worth effect is positive while the scale effect can be either positive (if the expression in brackets is positive, i.e. if the interest rate on trade credit is "sufficiently high" and/or the interest rate on bank loans is "sufficiently low") or negative (if the opposite holds true).

The profit of the $z-t h$ bank is $\pi_{z t}=\sum_{i \in I_{z}}\left(1+r_{z t}^{i}\right) B_{i t}+\sum_{j \in J_{z}}\left(1+r_{z t}^{j}\right) B_{j t}$

where $I_{z}$ and $J_{z}$ are, respectively, the set of $\mathrm{D}$ and $\mathrm{U}$ firms interacting with bank z. ${ }^{5}$ Substituting (4) and (5) we get

$$
\pi_{z t}=\sum_{i \in I_{z}}\left(1+r_{z t}^{i}\right)\left(w \delta_{d} \phi A_{i t}^{\beta}-A_{i t}\right)+\sum_{j \in J_{z}}\left(1+r_{z t}^{j}\right)\left(w \delta_{u} \gamma \phi \sum_{i \in \Phi_{j}} A_{i t}^{\beta}-A_{j t}\right)
$$

An increase of $A_{z t}$ affects $B_{z}$ 's profit for the simple reason that it makes the interest rate charged by the bank to both $\mathrm{D}$ and $\mathrm{U}$ firms go down ( $B$ net worth effect).

$B_{z}$ 's profit is also affected by the financial conditions of $\mathrm{D}$ and $\mathrm{U}$ borrowers through the following externalities:

- an increase of the net worth of $D$ and $U$ borrowers affects $B_{z}$ 's profit because it makes their leverage decrease so that the interest rate charged by the bank to these borrowers, i.e. $r_{z t}^{i}$ and $r_{z t}^{j}$ go down ( $D$ leverage and $U$ leverage effects);

- an increase of the net worth of $\mathrm{U}$ borrowers affects $B_{z}$ 's profit because it makes the volume of loans to $U$ customers decrease ( $U$ scale effect);

${ }^{5}$ Of course $I_{z} \cup J_{z}=\Phi_{z}$. 
- an increase of $D_{i}$ 's net worth makes the volume of loans to U customers increase while the volume of loans to $\mathrm{D}$ customers increases only if $\left(w \delta_{d} \phi \beta\right)^{\frac{1}{1-\beta}}>A_{i t}$ i.e. if the firm is not self financed ( $D$ scale effect).

Table 1 summarizes the effects of net worth of each type of agent on the profit of the same agent (on the main diagonal) and on the profits of the other agents (externalities, represented by off diagonal entries).

\begin{tabular}{|c|c|c|c|}
\hline \multicolumn{3}{|c|}{ Table 1. The effects of net worth on profit } \\
\hline & $\pi_{i}$ & $\pi_{j}$ & $\pi_{z}$ \\
\hline \multirow{3}{*}{$A_{i}$} & $\begin{array}{c}\text { scale e. }( \pm) \\
\text { D leverage e. }(+) \\
\text { D fin.gap e. }(+)\end{array}$ & scale e. $( \pm)$ & $\begin{array}{c}\text { D scale }( \pm) \\
\text { D leverage e. }(-)\end{array}$ \\
\hline \multirow{2}{*}{$A_{j}$} & U net worth e. $(+)$ & $\begin{array}{c}\text { U net worth e. }(-) \\
\text { U leverage e. }(+) \\
\text { U fin.gap e. }(+)\end{array}$ & $\begin{array}{c}\text { U scale e. }(-) \\
\text { U leverage e. }(-)\end{array}$ \\
\hline$A_{z}$ & Bank's net w.e. $(+)$ & Bank's net w.e. $(+)$ & Bank's net w.e. $(-)$ \\
\hline
\end{tabular}

As will become clear in the following section, profits are an important determinant of the flow of new net worth: the higher profits today, the higher will be net worth tomorrow. Table 1 therefore provides a rich and complicated picture of interactions among the financial conditions of the agents involved $\left(D_{i}, U_{j}, B_{z}\right)$.

For instance, the first column represents the impact of an increase of net worth of $D_{i}, U_{j}, B_{z}$ on $D_{i}$ 's profits. There are obvious self-reinforcing mechanisms at work. If the net worth of $D_{i}$ is growing, it is likely to grow bigger in the future due to the $\mathrm{D}$ leverage and $\mathrm{D}$ financing gap effects. $D_{i}$ can also benefit, in terms of profits and net worth accumulation, from an increase of $U_{j}$ 's and $B_{z}$ 's net worth, due to the $\mathrm{U}$ and B net worth effects.

There are, however, also self-stabilizing mechanisms, which work mainly through the banking system. An increase of $U_{j}$ 's and $D_{i}$ 's net worth, for instance, tends to depress the accumulation of the bank's net worth due to the leverage effect and the U scale effect. The co-existence of self-reinforcing and self-stabilizing mechanisms is the source of the oscillating behaviour of aggregate time series generated by the simulations that we will review in section 8 . 


\section{$7 \quad$ Bad debt and net worth}

In our framework, the $U$ firms and the banks are lenders while both types of firms can be borrowers (if they are not self-financed).

D firms therefore are pure borrowers. At the end of the period, the net worth of the $i-t h \mathrm{D}$ firm is defined as follows

$$
A_{i t+1}=A_{i t}+\pi_{i t}
$$

i.e. profits are the flow of new net worth. The $\mathrm{D}$ firm goes bankrupt if $A_{i t+1} \leq 0$ i.e. if it incurs a loss (negative profit) and the loss is big enough to deplete net worth:

$$
\pi_{i t} \leq-A_{i t}
$$

The net worth of D firms is the "engine" of fluctuations for the entire economy. In fact, by means of (1) $D_{i}$ 's net worth determines $D_{i}$ 's output, which in turn generates the demand for intermediate goods produced by $U$ firms. As a consequence also the demand for labour of the D and $U$ firms are determined by the net worth of $\mathrm{D}$ firms.

Substituting (11) into (14) we get:

$$
A_{i t+1}=A_{i t}+\left[u_{i t}-\left(1+r_{j t}\right) \gamma-\left(1+r_{z t}^{i}\right) w \delta_{d}\right] \phi A_{i t}^{\beta}+\left(1+r_{z t}^{i}\right) A_{i t}
$$

The net worth of the $\mathrm{D}$ firm in $\mathrm{t}+1 A_{i t+1}$ depends in a non linear way on $A_{i t}$ but also on the net worth of the $\mathrm{U}$ supplier - which determines $r_{j t}$ as defined in (3) - and on the net worth of the bank, which enters into (8).

The net worth of the $x-t h$ lender ( $x=j$ for $\mathrm{U}$ firms, $z$ for banks) is defined as follows

$$
A_{x t+1}=A_{x t}+\pi_{x t}-B D_{x t}
$$

where $B D_{x t}$ is "bad debt". In fact, if a borrower cannot pay back the loan obtained from the lender and goes bankrupt, the lender has a bad debt (nonperforming loan), that is accounted for as a reduction of its net worth. The lender goes bankrupt if $A_{x t+1} \leq 0$ i.e. if

$$
\pi_{x t}+A_{x t} \leq B D_{x t}
$$

In principle therefore, the lender can go bankrupt even profits are still positive if non-performing loans are high enough to wipe out net worth. 
Substituting (12) into the definition, $U_{j}$ 's net worth turns out to be

$$
A_{j t+1}=A_{j t}+\left[\left(1+r_{j t}\right)-\left(1+r_{z t}^{j}\right) w \delta_{u}\right] \gamma \phi \sum_{i \in \Phi_{j}} A_{i t}^{\beta}+\left(1+r_{z t}^{j}\right) A_{j t}-B D_{j t}
$$

In the case of $\mathrm{U}$ firms, bad debt is $B D_{j t}=\left(1+r_{j t}\right) \gamma \sum_{i \in \Phi_{j}^{B}} Y_{i t}$ i.e. the amount of trade credit not reimbursed (intermediate goods not paid for) by bankrupt D customers, which are grouped for convenience in the set $\Phi_{j}^{B}$. The net worth in t+1 $A_{j t+1}$ depends in a non linear way on $A_{j t}$ but also on the net worth of the $\mathrm{D}$ customers, which determines output of the $\mathrm{U}$ firm and bad debt (the set of bankrupt firms is a subset of D customers of the $\mathrm{U}$ supplier) - and on the net worth of the bank, which enters into (10).

Substituting (13) into the definition, the net worth of the bank turns out to be

$$
A_{z t+1}=A_{z t}+\sum_{i \in I_{z}}\left(1+r_{z t}^{i}\right)\left(w \delta_{d} \phi A_{i t}^{\beta}-A_{i t}\right)+\sum_{j \in J_{z}}\left(1+r_{z t}^{j}\right)\left(w \delta_{u} \gamma \phi \sum_{i \in \Phi_{j}} A_{i t}^{\beta}-A_{j t}\right)-B D_{z t}
$$

In the case of banks, "bad debt" is $B D_{z}=\sum_{i \in \Phi_{z}^{B}}\left(1+r_{z t}^{i}\right) B_{i t}+\sum_{j \in \Phi_{z}^{B}}\left(1+r_{z t}^{j}\right) B_{j t}$ i.e. non-performing loans of bankrupt D and U firms, which are grouped for convenience in the set $\Phi_{z}^{B}$. The net worth of the D and $\mathrm{U}$ borrowers codetermines the evolution over time of $A_{z t+1}$.

Finally, we assume a simple mechanism of entry-exit: bankrupt firms/banks are replaced with new entrants on the basis of a one-to-one replacement. ${ }^{6}$

\section{Simulations}

We explore the dynamic properties of the network economy modelled above by means of computer simulation. We consider an economy consisting of $I=500 \mathrm{D}$ firms, $J=250 \mathrm{U}$ firms and $Z=100$ banks over a time span of

\footnotetext{
${ }^{6}$ Accordingly, the total number of agents in the economy is constant over time. New agents are endowed with an initial amount of net worth drawn from a uniform distribution with mean 1 and finite variance. We assume the entrant is small relative to the size of the incumbent firms.
} 
$T=1000$ periods. There are 12 parameters in the model, which are set as follows:

Table 2. Parameter setting

\begin{tabular}{|l|l|l|}
\hline financially constrained output of D firms & $\phi=1.5$ & $\beta=0.8$ \\
\hline labour requirement of D and U firms & $\delta_{d}=0.5$ & $\delta_{u}=1$ \\
\hline intermediate goods requirement of D firms & $\gamma=0.5$ & \\
\hline interest rate on trade credit & $\alpha=0.1$ & \\
\hline interest rate on bank loans & $\sigma=0.1$ & $\theta=0.05$ \\
\hline real wage & $w=1$ & \\
\hline number of potential partners & $M=5$ & $N=5$ \\
\hline probability of preferred-partner choice & $1-\varepsilon=0.99$ & \\
\hline
\end{tabular}

The net worth of each $\mathrm{D}$ and $\mathrm{U}$ firm and of each bank at the beginning of the time horizon is set to 1.

Figure 1 shows the time series of aggregate $\mathrm{D}$ production obtained by adding up the production of $\mathrm{D}$ firms. Aggregate $\mathrm{U}$ production follows the same dynamic pattern since $U$ suppliers produce intermediate goods for D production "on demand". As expected, in a complex adaptive system fluctuations are irregular. Amplitude and periodicity vary wildly from sub-period to sub-period.

Starting from identical initial conditions firms become rapidly heterogeneous. ${ }^{7}$ Over time, a power law distribution of firms' size emerges (see figure 2 ), a result roughly in line with the evidence on the empirical firms'size distribution (Axtell, 2001; Gaffeo et al.,2003). Once again this is not surprising since the economy we are considering is characterized by heterogeneous interacting agents.

In addition, the distribution of the number of links (connectivity) for each lender ( $\mathrm{U}$ firm or bank) becomes asymmetric over time due to the preferredpartner choice governing the interaction among borrowers and lenders. In

\footnotetext{
${ }^{7}$ In each period, each D firm is hit by a price shock because the relative price is stochastic as explained in section 2. Therefore the accumulation of net worth on the part of each $\mathrm{D}$ firm rapidly takes different routes. The accumulation of net worth on the part of U firms and banks is determined as a consequence. Neither $\mathrm{U}$ firms nor banks, however, are subject to individual shocks.
} 
other words the degree distribution of the credit network suggests that the number of customers of lenders in the right tail of the distribution is higher than that generated by a normal distribution (see figure 3 ). The degree distribution, therefore, tends to a power law.

In the literature on evolving networks, a power law degree distribution is generated when the choice of the partner is governed by preferential attachment (Barabàsi and Albert, 1999), which is based on the assumption that nodes characterized by a relatively high number of links ("hubs") attract more new links than nodes with a small number of connections. Preferential attachment plays the role of a self-reinforcing mechanism: the higher the number of links of a certain node today, the higher will be the number of new links attached to that node tomorrow.

We do not make this ad hoc assumption but the same outcome occurs in our model due to the preferred-partner choice rule. Agents characterized by more robust financial conditions, in fact, can charge lower prices and attract more new partners. As a consequence, their profits go up and their financial conditions improve, making room for even lower prices in the future and attracting more new partners. In a sense the preferred-partner choice rule makes preferential attachment endogenous, through a mechanism similar to that described in physics as fitness model (Bianconi and Barabàsi, 2001).

Financially robust lenders can supply credit at better conditions and therefore increase their market share, i.e. attract a higher number of links. Financially sound U firms (resp. banks) set lower prices (interest rates), attract more D firms (borrowers), are more profitable and further increase their financial robustness. The opposite holds true for financially fragile lenders. Both the corporate and the banking sector therefore become polarized and the degree distribution becomes asymmetric.

This polarization process increases the vulnerability of the network to a shock - i.e. systemic risk - because the default of a highly connected agent, albeit a relatively rare event, may generate an avalanche of bankruptcies. The likelihood of this phenomenon depends on the structure of the network.

A typical story is the following. Suppose that $D_{i}$ belonging to $\Phi_{j}$ does not fulfill its debt obligations towards $U_{j}$ and goes bankrupt in t. $U_{j}$ will record a non-performing loan equal to the value of the intermediate goods not paid for by $D_{i}$ so that its net worth will go down next period. If $U_{j}$ were already fragile and/or the loan extended to $D_{i}$ were big, $U_{j}$ would go bankrupt in $t+1$. If it survives the shock, the reduction in net worth will lead the bank to 
charge a higher interest rate $r_{z t+1}^{j}$ due to the $\mathrm{U}$ leverage and $\mathrm{U}$ financing gap effect. Therefore also $U_{j}$ can go bankrupt in one of the following periods.

The deterioration of the bank's financial condition due to the borrowers' bankruptcies may be absorbed if the size of the loans is small enough and/or the bank's net worth is high enough. If this is not the case, also the bank goes bankrupt. An avalanche of bankruptcies will follow due to the positive feedback of the bankruptcy of a single agent on the net worth of the "neighbours", linked to the bankrupt agent by trade or credit links. For empirical evidence on this phenomenon see Fujiwara (2007).

The extent of bankruptcy avalanches depends on the amount of bad debt (see figure 4). Bankruptcy avalanches amplify business fluctuations. As a consequence, the distribution of aggregate growth rates is far from being Gaussian. It can be likened to a double exponential distribution with an asymmetry for negative events (see figure 5).

In order to assess the robustness of our findings, we perform a series of 100 Monte Carlo (MC) simulations in the two following alternative scenarios:

- preferred-partner choice (PPC)

- random matching $(\mathrm{RM}) .^{8}$

Figure 6 shows the degree distributions of the evolving (PPC) and the random (RM) networks. When the PPC rule is at work the degree distribution is right-skew while this is not the case if the network evolves according to a RM process. A similar result concerns the evolution of the firm size distribution: the PPC rule yields a right-skew (power law) distribution of firms' size, while this is not the case when agents are linked at random (see figure 7).

In table 3 we report some statistics on aggregate growth rates (GR), bad debt (BD), the correlation between aggregate production (business cycle) and debt-to-equity ratio (aggregate leverage ratio), bankruptcy probabilities, and the correlation across sectors. Since distributions are generally non-normal, we make use of robust statistics for the analysis of the location (median)

\footnotetext{
${ }^{8}$ The RM scenario is obtained from the first one setting $\varepsilon=1$. In the RM case the interaction among agents is no longer due to the endogenous process described above; instead, in each period, each agent interacts with another agent picked at random in the population of potential partners.
} 
and scale (median absolute deviation) parameters. ${ }^{9}$ We also compute robust measures of skewness (Groeneveld and Meeden, 1984) ${ }^{10}$ and kurtosis (Moors, 1988). ${ }^{11}$ For each variable in the table we report the average value and the standard deviation (in parenthesis) across MC simulations.

The average growth rate (GR) of aggregate production is $0.13 \%$ both in $\mathrm{RM}$ and in PPC. The median of GR and the volatility of aggregate output measured by the standard deviation or the median absolute deviation of GR - are slightly higher in PPC than in RM. In both scenarios the distribution of GR is left-skew. The (negative) skewness, however, is higher in absolute value in PPC. In other words, MC simulations show that there is a higher incidence of negative events in PPC than in RM. Finally, in both scenarios the kurtosis is not too far from that of a normal distribution. It is slightly higher, however, in RM than in PPC.

It is worth noting that "traditional" and "robust" measures of aggregate growth rates' statistical properties provide similar qualitative results. The only relevant difference between RM and PPC is due to the higher incidence of negative events in the distribution of aggregate growth rates in PPC, resulting in a higher (negative) skewness of GR in PPC.

The median of the aggregate bad debt (BD) - that is the sum of the bad debt of upstream firms and banks - and the (robust) measures of skewness and kurtosis are quite similar in the two settings. ${ }^{12}$ It is worth noting the high level of skewness in both cases, signaling a right-skew distribution of BD, with a relevant role of "extreme events", potentially leading to bankruptcy propagation across the network due to the incidence of non-performing loans on agents' balance sheets. Instead, the volatility of BD (e.g., the median absolute deviation) is higher in PPC than in RM.

\footnotetext{
${ }^{9}$ The median absolute deviation is the median of the absolute values of the deviations from the data's median.

${ }^{10}$ The robust measure of skewness (SK) is calculated as follows: $S K=\left(\mu-Q_{2}\right) / E \mid y_{t}-$ $Q 2$, where $y_{t}$ represents the data, $\mu$ is the mean, and $Q_{2}$ is the median. The SK statistic has zero value for Gaussian data; the lower bound is -1 and the upper bound is +1 .

${ }^{11}$ The robust measure of kurtosis $(\mathrm{KR})$ is calculated as follows: $K R=\left[\left(E_{7}-E_{5}\right)-\right.$ $\left.\left(E_{3}-E_{1}\right)\right] /\left(E_{6}-E_{2}\right)-1.23$, where $E_{i}$ is the i-octile of the distribution and 1.23 is the value of $\mathrm{KR}$ for a normal distribution $\mathrm{N}(0,1)$. Accordingly, $\mathrm{KR}$ is equal to zero in the case of Gaussian data.

${ }^{12}$ In this case we do not report "traditional" measures, because of the relevant discrepancies, for example, between the mean and the median or the standard deviation and the median absolute deviation. We report only robust statistics which are more accurate in describing highly asymmetric non-normal distributions.
} 
Differently from an "island" economy, in the case of "direct interaction" the default of one or more agents in a sector can propagate to other sectors, increasing the likelihood of bankruptcy avalanches and negative events at the aggregate level due to the deterioration of financial conditions. In order to investigate this point, we compute the correlation between the number of bankruptcies in different sectors and the default probability for different typology of agents.

From table 3 we infer that there are positive correlations between bankruptcies in different sectors: the coefficient of correlation between $\mathrm{D}$ and $\mathrm{U}$ defaults and between $\mathrm{D}$ and $\mathrm{B}$ defaults is a modest $0.2-0.3$. Instead, the default of $\mathrm{U}$ firms considerably affects the B bankruptcies: in this case the coefficient of correlation is $0.7-0.8$. Although the correlation coefficients are slightly different, the linking process across sectors seems to produce similar results in PPC and RM, independently of the specific mechanism of interaction.

In general, the diffusion of bankruptcies originates in the defaults of one or more D firms that yield a deterioration of the financial conditions of $U$ firms, spread bankruptcies among $U$ firms and a propagation of the crisis to the banking sector.

While the correlation structure across sectors is similar in PPC and RM, bankruptcy probabilities vary significantly in the two settings. The total default probability (e.g., the probability that an agent fails in a given period) is equal to $10 \%$ in RM and almost $11 \%$ in PPC. Also the bankruptcy probability of D firms is quite similar in the two setting (16-17\%). Instead, the bankruptcy probability of $\mathrm{U}$ firms is $1 \%$ in $\mathrm{RM}$ and more than $2 \%$ in PPC. Furthermore, the bankruptcy probability of banks is $0.3 \%$ in RM and $3 \%$ in PPC. Accordingly, the endogenous formation of the network produces a configuration of productive and credit interlinkages that increases the probability of bankruptcy in the $\mathrm{U}$ sector (more than double with respect to $\mathrm{RM}$ ) and in the banking sector (ten times the RM level).

Even though the correlation among bankruptcies in different sectors is similar in the two scenarios, as said above, the greater incidence of defaults in the $U$ and banking sectors means that the endogenous network emerging from agents' choices increases the likelihood of bankruptcy propagation, starting from idiosyncratic shocks regarding D firms. In general, the evolving network economy seems to show a higher systemic risk with respect to a random network economy, as explained by the different effects of interlinkages configurations on bankruptcy propagation across sectors. 
Finally, the correlation between an average indicator of the aggregate leverage ratio, that is the debt-to-equity ratio, and the business cycle, that is aggregate production, is very different in the two scenarios: it is highly positive in RM while it is not significant in PPC. In other words, in the PPC scenario, differently from the RM case, the dynamics of the debt-to-equity ratio seems decoupled from the dynamics of the business cycle. Hence, while the random matching economy seems to be well described by an average indicator of financial conditions, this is not the case for the evolving network economy. We think that this fact is related to the different topology of the network governing agents' interactions. In the RM scenario the partner is picked at random, in each period of time, and the random network has a characteristic scale, that is the average degree distribution represents the typical scale of the number of links per agent; then, in this case the behaviour of the economy could be described by a "representative agent" with an average number of links and certain financial conditions. In the PPC scenario, instead, the endogenous choice of partners leads to a scale-free degree distribution. In this case there is no characteristic scale of the network. The high asymmetry of the degree distribution (e.g., many agents with a small number of links and few agents - hubs - with a very large number of links) does not allow to reduce aggregate dynamics to the average behaviour of a representative agent. However, this aspect requires further investigation. 
Table 3. Monte Carlo simulations: RM vs. PPC.

\begin{tabular}{|c|c|c|}
\hline & $R M$ & $P P C$ \\
\hline mean(GR) & $0.0013(0.0000)$ & $0.0013(0.0000)$ \\
\hline standard deviation(GR) & $0.0393(0.0018)$ & $0.0401(0.0025)$ \\
\hline skewness(GR) & $-0.1238(0.0838)$ & $-0.1393(0.0696)$ \\
\hline kurtosis(GR) & $2.9386(0.1510)$ & $2.9132(0.1657)$ \\
\hline median(GR) & $0.0022(0.0010)$ & $0.0025(0.0010)$ \\
\hline median absolute deviation(GR) & $0.0266(0.0014)$ & $0.0273(0.0020)$ \\
\hline robust skewness(GR) & $-0.0279(0.0315)$ & $-0.0356(0.0301)$ \\
\hline robust kurtosis(GR) & $0.0031(0.0521)$ & $-0.0018(0.0567)$ \\
\hline median(BD) & $37.2940(1.5381)$ & $36.8541(3.8340)$ \\
\hline median absolute deviation(BD) & $12.0540(1.2254)$ & $16.49(2.7380)$ \\
\hline robust skewness(BD) & $0.6612(0.0681)$ & $0.6518(0.0880)$ \\
\hline robust kurtosis(BD) & $0.4279(0.1523)$ & $0.4031(0.1918)$ \\
\hline bankruptcy rate: corr(D,U) & $0.2683(0.0327)$ & $0.2895(0.0261)$ \\
\hline bankruptcy rate: corr(D,B) & $0.2044(0.0324)$ & $0.2196(0.0295)$ \\
\hline bankruptcy rate: corr(U,B) & $0.7970(0.0240)$ & $0.7472(0.0194)$ \\
\hline bankruptcy rate: corr(D+U,B) & $0.4320(0.0327)$ & $0.4200(0.0284)$ \\
\hline bankruptcy probability & $0.1009(0.0000)$ & $0.1093(0.0011)$ \\
\hline bankruptcy probability: D & $0.1656(0.0000)$ & $0.1670(0.0000)$ \\
\hline bankruptcy probability: U & $0.0104(0.0000)$ & $0.0253(0.0014)$ \\
\hline bankruptcy probability: B & $0.0035(0.0000)$ & $0.0310(0.0022)$ \\
\hline corr(Debt-to-Equity,Y) & $0.6024(0.1540)$ & $-0.0453(0.2187)$ \\
\hline
\end{tabular}

\section{Concluding remarks}

We have explored the properties of a credit network characterized by inside credit (i.e. credit relationships connecting agents belonging to different groups of the same sector, i.e. D firms and U firms) and outside credit (i.e. credit relationships connecting agents belonging to different sectors, i.e. firms and banks).

The network structure changes over time due to the preferred-partner choice rule, which implies that endogenous changes of the interest rate on trade credit and on bank loans affect the number of clients of each $U$ firm and each bank. This rule has the same implication for the evolution of network topology as the preferential attachment rule but is not based upon an ad 
hoc assumption. On the contrary, the preferred-partner choice rule captures an important aspect of the agents' decision making, i.e. the choice of the partner offering the best bargain in terms of price. The changing topology of the network affects the propagation of bankruptcies and the shape of business fluctuations.

The borrower's net worth is a proxy of creditworthiness. Hence credit extended is increasing with the borrowers' net worth. Since D output which consists of consumption goods - is constrained only by the availability of funds, in the end, the supply of consumption goods is increasing with $\mathrm{D}$ net worth. The net worth of D firms turns out to be the driver of growth and fluctuations. U production, in fact, is determined by demand of intermediate inputs on the part of D firms. Changes in the D net worth, therefore, yield changes in the same direction of $\mathrm{U}$ production. Also banks are involved because the interest rate that a bank charges is a function of borrowers' net worth.

If a D firm goes bankrupt, not only the supply chain can be disrupted - involving $U$ firms - but also an interest rate hike can follow due to the change in attitude of lenders. More bankruptcies will follow in a bankruptcy avalanche.

The output of simulations shows that a business cycle at the macroeconomic level can develop as a consequence of the complex interaction of the financial conditions of the agents involved. We can also reproduce the main facts of firms' demography: power law distribution of firms' size and Laplace distribution of growth rates. The preferred choice rule affects essentially the skewness of the firms' size distribution and of the degree distribution of the network.

This is a step in a complex and difficult quest for a "complete" credit network. There are obvious restrictions on the conditions determining the model environment which we plan to relax in the future. For instance, we would like to extend the preferred choice rule also to the market for consumption goods and to the labour market. This will imply a more sophisticated design of households' behaviour, which so far has been essentially passive. Another obvious extension is the introduction of an interbank market, which will allow modelling the central bank and monetary policy. 


\section{References}

[1] Allen, F. and D. Gale (2001), "Financial Contagion", Journal of Political Economy, 108:1-33.

[2] Axtell R. (2001), "Zipf Distribution of U.S. Firm Sizes", Science, 293:1818-1820.

[3] Bak P., Chen K., Scheinkman J. and M. Woodford (1993), "Aggregate Fluctuations from Independent Sectoral Shocks: Self-Organized Criticality in a Model of Production and Inventory Dynamics", Ricerche Economiche, 47:3-30.

[4] Barabàsi A.-L. and R. Albert (1999), "Emergence of Scaling in Random Networks", Nature, 286:509-512.

[5] Battiston S., Delli Gatti D., Gallegati M., Greenwald B. and J.E. Stiglitz (2007), "Credit chains and bankruptcies avalanches in supply networks", Journal of Economic Dynamics and Control, 31(6):2061-2084.

[6] Bernanke, B. and M. Gertler (1989), "Agency Costs, Net Worth and Business Fluctuations", American Economic Review, 79:14-31.

[7] Bernanke, B. and M. Gertler (1990), "Financial Fragility and Economic Performance", Quarterly Journal of Economics, 105:87-114.

[8] Bernanke, B., Gertler, M. and S. Gilchrist (1999), "The Financial Accelerator in Quantitative Business Cycle Framework", in Taylor, J. and Woodford, M. (eds), Handbook of Macroeconomics, Vol. 1C, North Holland, Amsterdam.

[9] Bianconi G. and A.-L. Barabàsi (2001), "Competition and Multiscaling in Evolving Networks", Europhysics Letters, 54(4):436-442

[10] Boissay, F. (2006), "Credit chains and the propagation of financial distress", European Central Bank Working Paper, \#573.

[11] Boss M., Elsinger H., Summer, M. and S. Thurner (2004), "Network Topology of the Interbank Market", Quantitative Finance, 4(6):677-84.

[12] Bottazzi G. and A. Secchi (2003), "Why Are Distributions of Firm Growth Rates Tent-Shaped?", Economic Letters, 80:415-420. 
[13] Caldarelli, G. (2007), Scale-free Networks, Oxford University Press.

[14] Delli Gatti D., Di Guilmi C., Gaffeo E., Gallegati M., Giulioni G. and A. Palestrini (2005), "A New Approach to Business Fluctuations: Heterogeneous Interacting Agents, Scaling Laws and Financial Fragility", Journal of Economic Behavior and Organization, 56:489-512.

[15] Delli Gatti D., Gallegati M., Greenwald B., Russo A. and J.E. Stiglitz (2006), "Business Fluctuations in a Credit-Network Economy", Physica A, 370:68-74.

[16] Demange, G. and M. Wooders (2005), Group Formation in Economics: Networks, Clubs and Coalitions, Cambridge University Press.

[17] Freixas, X., Parigi, B. M. and J.C. Rochet (2000), "Systemic Risk, Interbank Relations and Liquidity Provision by the Central Bank", Journal of Money, Credit and Banking, 32:611-38.

[18] Fujiwara Y. (2007), "Chain of Firm Bankruptcy", mimeo, Kyoto University.

[19] Furfine, C.H. (2003), "Interbank Exposures: Quantifying the Risk of Contagion", Journal of Money, Credit and Banking, 35(1):111-28.

[20] Gaffeo E., Gallegati M. and A. Palestrini (2003), "On the Size Distribution of Firms. Additional Evidence from the G7 Countries", Physica A, 324:117-123.

[21] Goyal, S. (2007), Connections, Princeton University Press.

[22] Greenwald, B. and J.E. Stiglitz (1993), "Financial Market Imperfections and Business Cycles", Quarterly Journal of Economics, 108:77-114.

[23] Groeneveld R.A. and G. Meeden (1984), "Measuring Skewness and Kurtosis ", The Statistician, 33:391-399.

[24] Iori, G., S. Jafarey, and F. Padilla. (2006), "Systemic risk on the interbank market", Journal of Economic Behaviour and Organization, 61(4):525-540. 
[25] Jackson M.O. (2005), "The Economics of Social Networks", in Blundell R., Newey W. and T. Persson, Proceedings of the 9th World Congress of the Econometric Society, Cambridge University Press.

[26] Jackson M.O. (2008), Social and Economics Networks, Princeton University Press.

[27] Moors J.J.E. (1988), "A Quantile Alternative for Kurtosis ", The Statistician, 37:25-32.

[28] Nier E., Yang J., Yorulmazer T. and A. Alentorn (2007), "Network Models and Financial Stability", Journal of Economic Dynamics and Control, 31:2033-2060.

[29] Stanley M., Amaral L., Buldyrev S., Havlin S., Leschorn H., Maas P., Salinger M. and E. Stanley (1996), "Scaling Behavior in the Growth of Companies", Nature, 379:804-806.

[30] Stiglitz J.E. and B. Greenwald (2003), Towards a New Paradigm in Monetary Economics, Cambridge University Press.

[31] Vega-Redondo F. (2007), Complex Social Networks, Econometric Society Monograph Series, Cambridge University Press. 


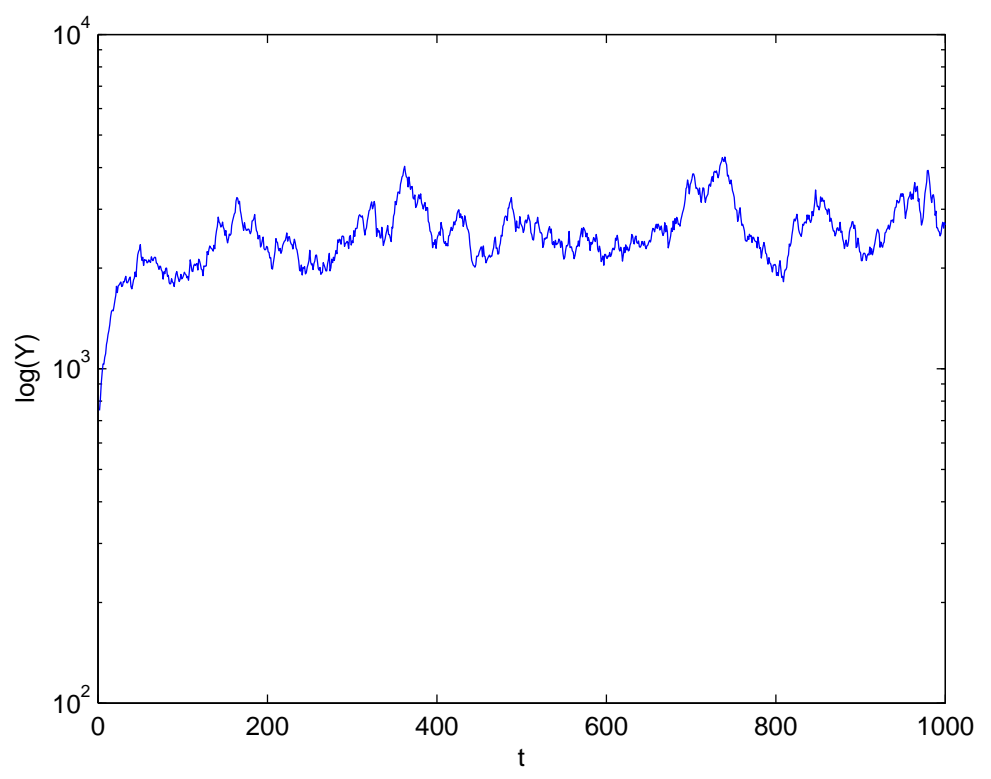

Figure 1: Aggregate Production

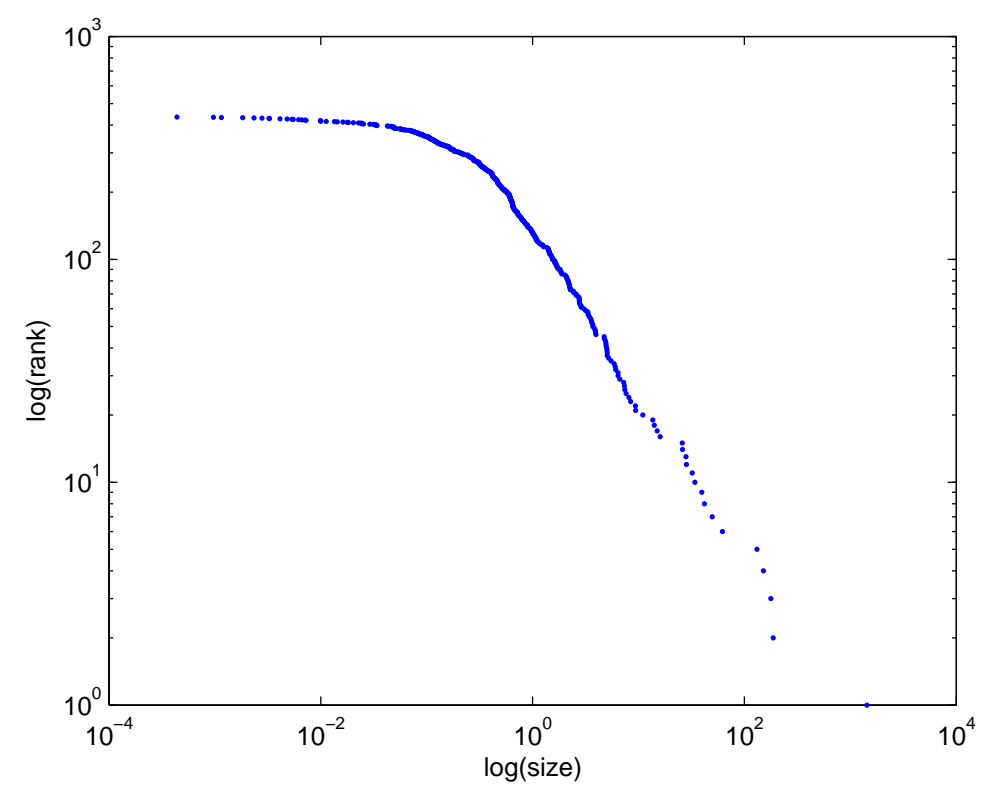

Figure 2: Firms size distribution (in terms of net worth) 


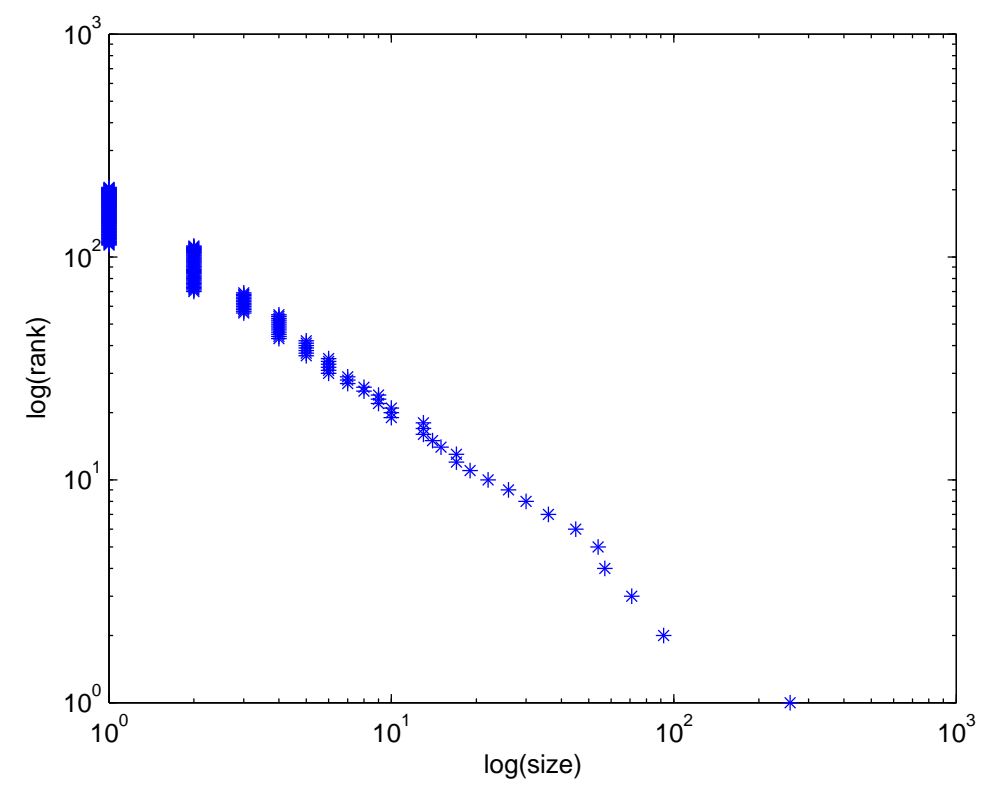

Figure 3: Degree distribution of the network

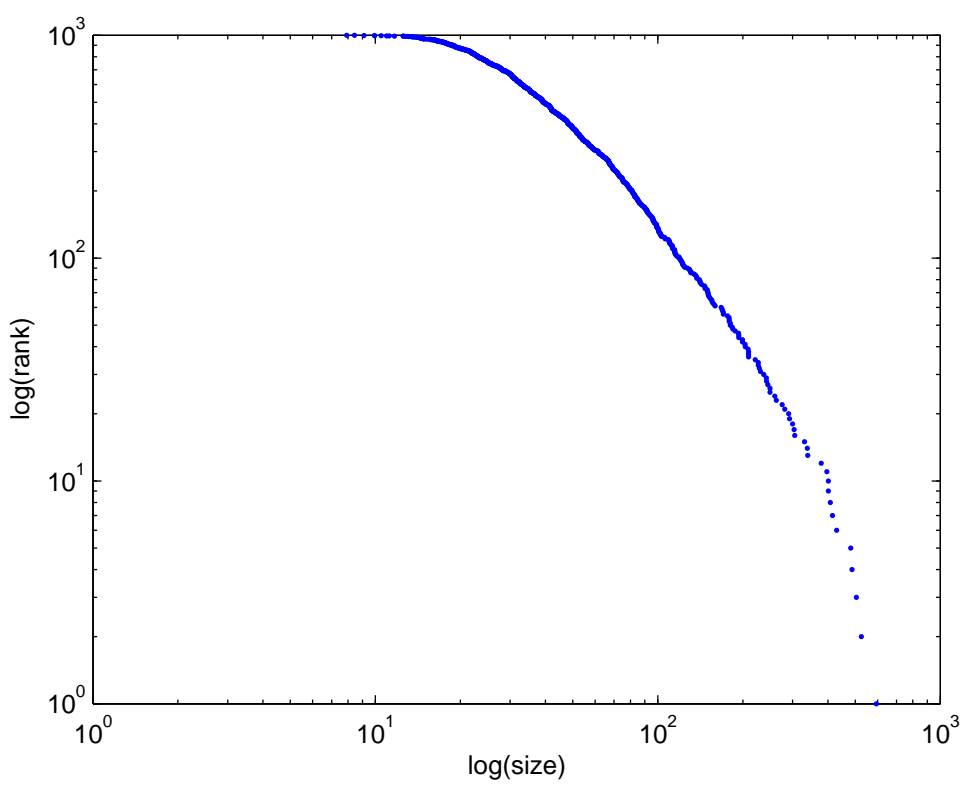

Figure 4: The distribution of bad debt 


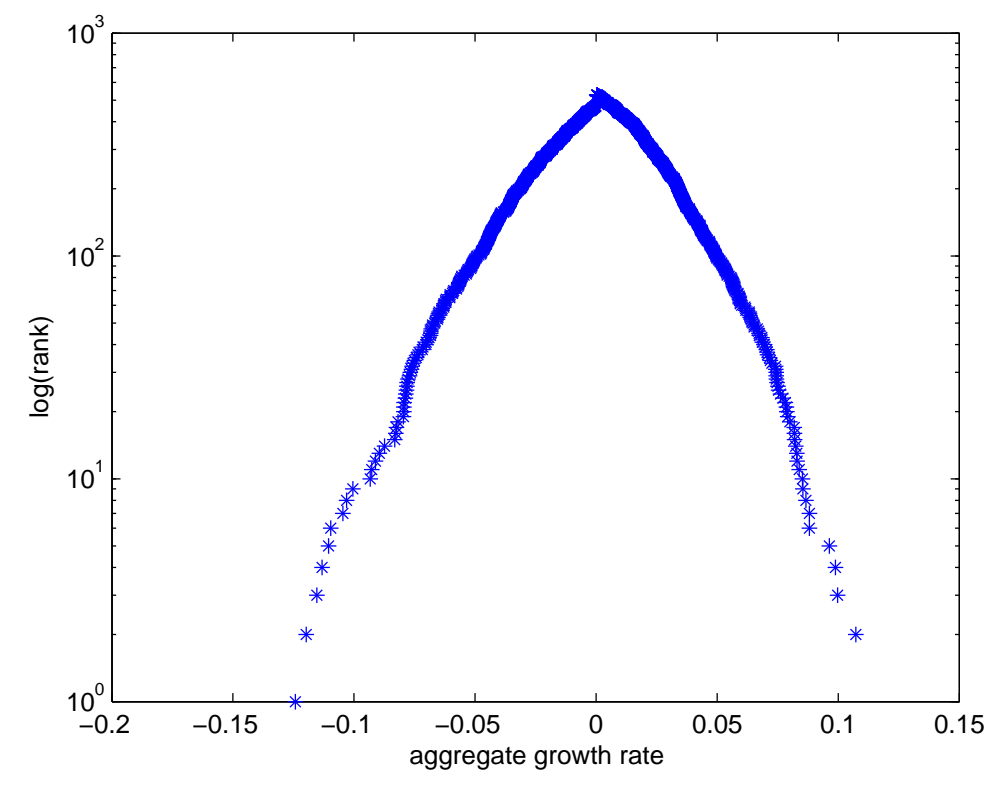

Figure 5: The distribution of aggregate growth rate

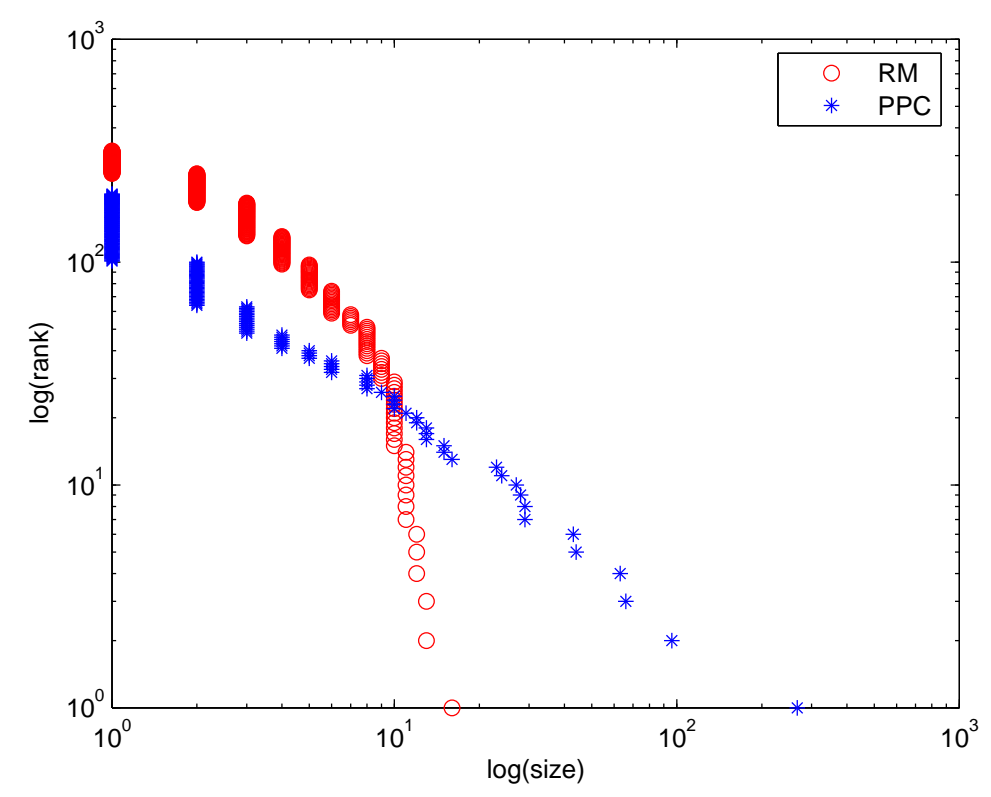

Figure 6: Degree distribution of the network: RM vs. PCC 


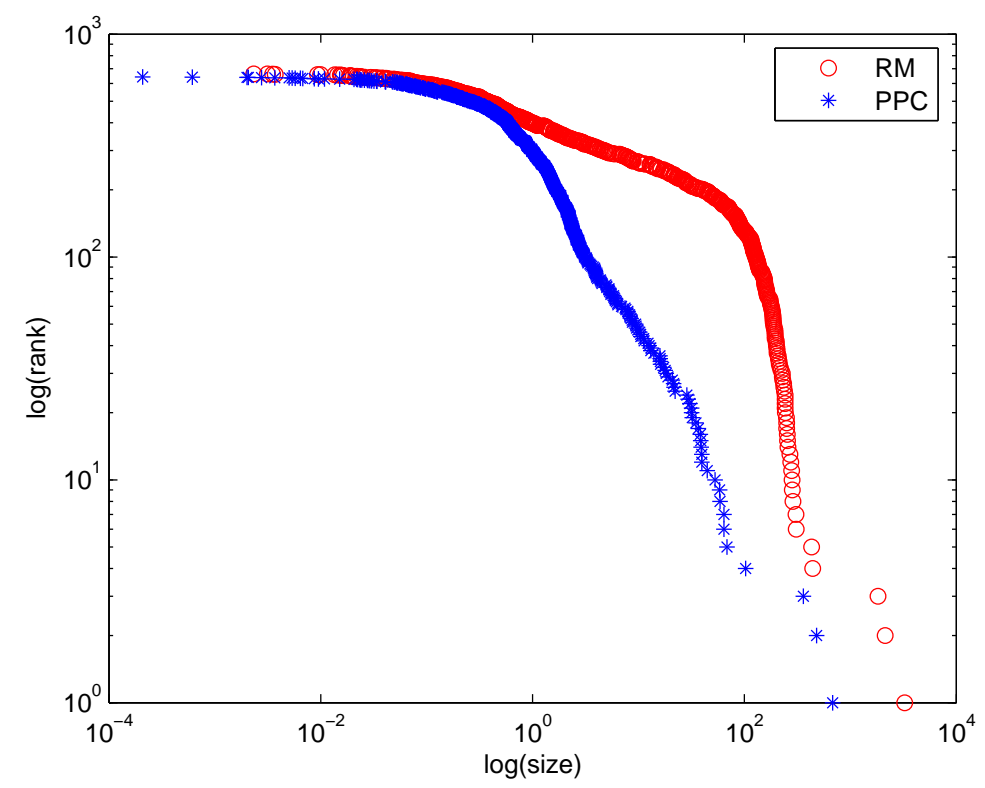

Figure 7: Firm size distribution: RM vs. PCC 